\title{
HUELLAS DE DIEGO SILOEE EN MEXICO
}

\author{
$\mathbf{P} \mathbf{O}$
}

\section{A N UEL TOUSSA I N T}

$\bigcup^{N O}$ de los más interesantes motivos de estudio para los historiadores del arte de la América española, radica en poder identificar la paternidad estilística de los más valiosos monumentos. Si hemos podido reconstruir con bastante aproximación el desarrollo del movimiento plástico en Nueva España, en relación con el de la metrópoli; marcar sus grandes épocas, si no paralelas sí equidistantes, por la separación del océano del tiempo; sus directrices fundamentales de forma y de adaptación a un país que se estaba creando a sí mismo y que, al llegar a su madurez adopta una expresión de arte propia, importada pero teñida de matices diferenciales, un lenguaje plástico, en fin, que permite crear, en explosiones incontenibles, la gran arquitectura religiosa de nuestro siglo xvin, jalón del nacionalismo artístico mexicano; por lo que se refiere a los tipos aislados sabemos aún muy poco. Modificaciones impuestas por numerosas causas: el medio, los recursos económicos o de materiales, la influencia indígena persistente en la mano de obra, imprimen al edificio, las más de las veces, un aspecto de exotismo inevitable. Pero lo exótico no implica originalidad o diferenciación absoluta. Es decir, que elementos puros pueden aparecer en un edificio que en el conjunto de su estilo es exótico. Tales la capilla abierta de Tlalmanalco, las posas de Calpan, la gran fachada del templo de Yuririapúndaro y tantos otros de nuestro siglo xvi. La observación se extiende hasta el siglo xvirı: cualquiera que estudie en detalle los relieves que constituyen la preciosa portada churrigueresca del templo de 
Tepotzotlán, puede notar que gran parte de sus motivos ornamentales son del más puro renacimiento.

Que los mismos artífices creían realizar obras clásicas cuando dejaban volar su fantasía en esos interiores fantásticos, lo prueban las descripciones contemporáneas que conservamos de los monumentos: allí no se habla sino de columnas, pilares o pilastras, entablamentos con su arquitrabe, friso y cornisa, etc. Si suprimimos los cartones, las volutas, los róleos, los estípites, parece que nos encontramos frente a un Partenón y... ¡ he aquí que se trata del más desenfrenado barroquismo, colindante con la demencia!

Por eso juzgo de interés apuntar, asi sea someramente, los rastros que cualquiera de los grandes creadores del arte español haya dejado en los monumentos de América, bien directamente, a través de discípulos o imitadores; bien de modo indirecto por reminiscencias. Primicias de un estudio en que trabajo acerca de la Arquitectura del Renacimiento en Nueva España son estas notas. Los más destacados arquitectos que laboraron en México en la segunda mitad del siglo xvi fueron Hernando Toribio de Alcaraz, Claudio de Arciniega, Francisco Becerra, Diego de Aguilera, Juan Miguel de Agüero y Antonio Ortiz. Organizando la biografia de cada uno de ellos, en lo posible, y relacionando su labor en un estudio preliminar en que se incluyen aquellas obras aún anónimas, se alcanza la meta. Por ahora sólo me propongo marcar las huellas de uno de los más notables artífices de la España renacentista, Diego Silóee, en nuestra arquitectura virreinal. Es esto posible gracias a dos excelentes libros españoles: Aguilas del Renacimiento Español, de Manuel Gómez Moreno y Fuentes para la historia del Arte Hispanoamericano, de Enrique Marco Dorta.

La importancia de Diego Silóee es bien conocida. Gómez Moreno la resalta admirablemente en un sólo párrafo: "Silóee personifica en arte el sentir español en su fase más rica, maás a tono con nuestros esplendores meridionales, y en armonía con el ansia de fastuosidad que el Renacimiento impuso con las formas clásicas, traídas como simple moda para nosotros, de Italia. Con Silóee afrontamos el problema de cómo las presiones del medio social actúan sobre un temperamento adaptable a los gustos y urgencias de cada hora, sin hacerle perder iniciativas; antes, al contrario, difundiendo su espíritu en torno. De modo que él, acaso, entre sus colegas españoles resulte el más hábil forjador de discípulos, 
aunque ellos, como de ordinario, le quedasen zagueros." 1 En los arquitectos de Nueva España esta ductilidad del criterio característico del maestro, llega al extremo. Y no podía ser de otro modo. Cada templo, cada monasterio, cada edificio implica problemas diversos. El artista tiene que plegarse a necesidades cambiantes a cada momento. Además no es uno solo el que construye cada obra sino varios, a veces muchos, en el transcurso de los años que tardaba la fábrica. Saber conservar, por encima de todas estas urgencias, el criterio artístico, el verdadero sentido arquitectónico es lo que enaltece y glorifica a los legítimos creadores de arte. Los demás no son sino albañiles, sobrestantes o a lo sumo maestros de obras.

$\mathrm{Ha}$ sido registrada ya una imitación del arte de Silóee por los señores Gómez Moreno y Angulo: los soportes de muchos templos están compuestos por un pilar de sección cuadrada al que se adosan cuatro medias columnas en sus caras. Como el fuste de éstas resulta alargadísimo y por tanto fuera de los cánones, se toma como unidad el conjunto pero, a mayor abundamiento, Silóee sobrepone a los capiteles un entablamento y cuando tiene que soportar la techumbre de una nave más alta, añade una pilastra que llega al arranque de las últimas bóvedas. El ejemplar más suntuoso de este sistema lo desarrolló en la catedral de Granada, pero "hizo escuela en todo el mediodia español y aún trascendió a América". ${ }^{2}$ Angulo lo nota en la catedral de Guadalajara pero la imitación se prolonga hasta bien entrado el siglo xviII, como vemos en la iglesia de la Compañía de Jesús en Puebla que data de 1767. Compárese este interior con el de la Catedral de Granada y podrá apreciarse la semejanza que llega a la identidad. (Figs. 2 y 3.)

Puede afirmarse, sin género de duda, que Claudio de Arciniega, el más famoso arquitecto del Renacimiento en Nueva España, conocía bien la región de Granada y por ende, la obra de Silóee. Éntre 1541 en que trabaja en el alcázar de Madrid, bajo las órdenes de Luis de Vega acaso, y 1554 que aparece por primera vez en Puebla, transcurren bastantes años. En ellos debe haber trabajado en diversas regiones de España y conocido, por ende, las obras de los grandes maestros del Renacimiento.

Cuando concluye la portada del templo de San Agustín de México en 1579 la describe de este modo: "Primeramente en los quatro pilares quadrados de la delantera de la yglesia que están a los lados de la por-

1 Manuel Gómez Moreno. Aguilas... p. 35.

2 Aguilas... p. 107. 
tada principal se han labrado y asentado quatro hiladas de piedra de cantería con sus capiteles jónicos con que se remataron los dichos quatro pilares.- Iten, se ha labrado y asentado sobre los dichos capiteles un alquitrave de moldura con su friso pulvinato (es decir acojinado, convexo), en todo lo que toman de ancho los dos lados de la portada hasta la portada principal $y$ en el un lado de estos, sobre el friso, tiene labrada y asentada una cornija de molduras ... Iten, sobre la cornija de la portada principal quedaron labrados y asentados quatro zócalos de cantería con quatro colunas sobre las dichas vasas; desde la última visita se an tanbién labrado y asentado con sus capiteles, las quales van acanaladas $\mathrm{y}$ los tercios altos labrados de talla al romano que siruen de hornato y acompañamiento a la segunda horden de la dicha portada.- Iten, entre las dichas colunas se an labrado y asentado dos encasamentos con sus repisas veneras y sus remates encima de ellas, que todo va labrado de talla, los quales encasamentos an de seuir para poner dos sanctos en ellos.Iten, encima de la portada principal de medio a medio della sobre la cornixa, se a asentado una ystoria grande del señor San Agustín con las órdenes en ella con figuras mayores que de el natural ..."3

Si se compara esta descripción con la portada principal del templo de San Salvador de Ubeda (Fig. 1), obra de Andrés de Vandaelvira y Alonso Ruiz, copiando la puerta del Perdón de la catedral granadina creación cumbre de Silóee, vemos que Arciniega aprovechó varios elementos. Desde luego, la disposición general : dos entrecalles con hornacinas en ellas, la puerta al centro $\mathrm{y}$ un gran relieve arriba. $\mathrm{El}$ arquitecto encontró cuatro pilares a los que sólo faltaban los capiteles; él, seguramente hubiese puesto columnas. Para éstas emplea el tipo de Ubeda: acanaladas y con el último tercio esculpido a lo romano, en contra de lo habitual que es ornamentar el primer tercio; las hornacinas con su venera arriba, no sabemos si con la charnela en alto como en el modelo preferido por Silóee. El friso "pulvinato", acojinado, como quiere Vitrubio para lo jónico" y como lo había empleado en el Túmulo imperial. Nótese que el segundo cuerpo de la portada de Ubeda es francamente defectuoso.

Otras observaciones nos sugiere esta portada. Desde luego es el tipo que seguirian casi todas las que se edificaron en el resto del arte del coloniaje. Si la comparamos con la de Acolman, anterior en diez y nueve

3 Enrique Marco Dorta. Fuentes... pp. 123-4

4 Lib. III, Cap. III. 
años, notamos gran diferencia: ésta es propiamente de un sólo cuerpo, con elementos platerescos como la ventana, los escudos, los medallones, las columnas abalaustradas, que aquí han cedido el puesto a un ordenamiento más clásico, más arquitectónico, más purista.

Existe otra referencia a Silóee de forma más indirecta: su nombre se relaciona con el de otro arquitecto famoso que figura en Nueva España a fines del siglo xvi: Diego de Aguilera. En efecto, en la Información que hizo para obtener el cargo de familiar del Santo Oficio en 1594, las declaraciones de los testigos permiten bosquejar parte de su biografía: "Diego de Aguilera debió nacer allá por el año de 1547 en la Villa de Iznalloz, en la provincia de Granada, donde por entonces trabajaban su padre y hermano -el uno como maestro y el otro como asentador- en la construcción de la iglesia mayor de dicho pueblo, 'una de las mejores de Andalucía' y su ejecutor 'Alonso de Aguilera, muy afamado maestro del arte de arquitectura', según la declaración de uno de los testigos. Nace Diego de Aguilera en un medio donde la tradición gremialista de tallar la piedra y construír grandes templos, tiene ya claro exponente en su padre y hermano Ambrosio. Al lado de ellos aprendió el oficio y 'siendo muy mozo se salio de la dicha Villa de Iznalloz y anduvo algunos años por España trabajando en el arte de arquitectura'. Busca trabajo en los grandes centros ' $y$ yo e comunicado con él siete años en los Reinos de Castilla, en Aranjuez, donde le vi la primera vez trabajando en su oficio de cantería, y el demás tiempo en esta Nueva España, el cual será de edad de cuarenta y seis años, poco más o menos' (Declaración de Lucas López.)" *

Ahora bien, Gómez Moreno nos dice: "Corría el año 1549 cuando Silóee trazó una iglesia de cierta importancia en la diócesis de Granada, y es la parroquial de Iznalloz, según asiento de pago: 'cuando fuimos el señor Antonio de Ovalle y Silóee a traçar la yglesia de Asnalloz'. Consta luego que dirigía su obra Juan de Maeda, entre 1566 y 1574, pero debió de comenzarse mucho antes..." 8 Efectivamente, podemos agregar ahora, fue empezada a raíz de su traza por Alonso de Aguilera y su hijo Ambrosio. Nuestro Diego tenía entonces tres años de edad, pero se educó en un medio de arquitectura renacentista. De ello dió prueba en las obras

5 El señor Luis Romero Solano descubrió esta información en el Archivo General y se publica en este mismo número de los Anales. El párrafo citado es de la nota preliminar.

6 Aguilas... p. 82. 
en que conocemos su intervención en Nueva España. Como continuador del purista Arciniega en el maestrazgo de la catedral de México, de 1593 a principios del siglo xvir, sólo puede haber continuado el proyecto sin alteración ninguna. El segundo testimonio es más explícito y se encuentra en el dictamen que dió en competencia con Martín Casillas, para la obra de la catedral de Guadalajara en la Nueva Galicia. En tanto que Casillas propuso que la techumbre fuese de bóvedas de cinco claves, es decir de crucería ojival, Aguilera opinó que deberían ser bóvedas "de piedra de teçontle llanas, sin labor ninguna, las quales an de yr cerradas todas en bueita de horno (vaídas) por ser el punto más alto y subido que no el de las capillas de aristas". Sin embargo, triunfó la tradición y se aceptó lo propuesto por Casillas: "El gótico, tan arraigado en Nueva España, se impuso así en la cubierta de una de las grandes catedrales del virreinato, y el viejo estilo medieval triunfó sobre el renacentista representado por las bóvedas vaidas que había propuesto Diego de Aguilera." 7

El último hallazgo relacionado con Silóee y el que me parece más importante se encuentra en Puebla en los restos de la portada de la antigua alhóndiga. Di cuenta del descubrimiento desde 1942 en estos Anales (N9 8, p. 75), marcando la importancia artística de los relieves, pero sin precisar su ascendencia estilística como lo hago ahora.

Es pertinente repetir la descripción: "Los restos de la portada encuéntranse en la calle 2 Oriente en el edificio que es hoy 'Cámara de Comercio de Industrias en pequeño' (En la actualidad, 1953, están instaladas en él las oficinas de los 'Seguros de Puebla, S. A.'). Constan de dos pares de columnas estriadas, semejantes a las de la famosa Casa de Montejo en Mérida de Yucatán y a las de la llamada casa del Deán, aqui en Puebla, fechada en 1580. Arriba, a los lados del balcón, ornatos renacentistas en forma de $\mathrm{S}$ con fajas vegetales como de acanto estilizado; en las extremidades de cada una dos cabezas humanas, las de arriba con alas como Mercurio, dios del comercio, una barbada y otra sólo con bigote, de hombre al parecer calvo, ambas de frente. Las dos de abajo están de perfil, con barbas que continúan la curva del ornamento, el róleo, y cuernos, lo que les da aspecto de sátiros. Las cuatro representan hombres ancianos. En la parte alta de las mismas piedras, en sus orillas interiores, querubines con mensulitas. Sobre cada ornato de los descritos aparecen medallones con figuras de busto en alto relieve: el de la derecha es un guerrero euro-

7 Enrique Marco Dorta. Idem. pp. 42-45. 
peo que blande una pequeña espada; el de la siniestra parece un 'salvaje' armado de una maza de tronco de árbol. Estos alto relieves son muy semejantes a los que se ven a los lados de la puerta en la casa llamada 'de las cabecitas' en Puebla, frente a la portada lateral del templo de San Agustín.

"En la parte alta, al centro se encuentra el escudo de la ciudad de Puebla, pero puede observarse que ha sido arreglado en el escudo de un particular, acaso el regidor o alcalde en cuyo tiempo fué esculpida la portada como era costumbre en esta ciudad y en otras muchas. Del blasón original queda el yelmo mirando a la izquierda con un águila posada en él y restos del lambrequín formado de ornatos vegetales y con cascabeles, como en la casa de Montejo, y el escudo propiamente dicho, cuyas divisas han sido sustituídas por un templo que reproduce la catedral actual con sus torres y cúpula en vez del castillo original del escudo. Destruyendo parte del lambrequín se han incrustado dos ménsulas sobre las cuales se colocaron ángeles de argamasa que se están destruyendo. Del yelmo surgen bellas plumas que se reparten armoniosamente en una especie de venera de nicho. $\mathrm{La}$ inscripción del escudo de Puebla se encuentra en la parte alta en el borde, y en la parte baja dentro del mismo escudo." (Figs. 6, 7, 8 y 9.)

Si comparamos estos ornatos en alto relieve en forma de $\mathrm{S}$ con los que se encuentran entre los adornos del sepulcro del obispo Don Rodrigo de Mercado en la iglesia parroquial de Oñate "obra indudable aunque no documentada de Silóee" veremos que su semejanza es inequivoca. Semejanza pero no identidad como conviene an obras una de maestro y otra de discípulo. No por eso se crea que la de América es inferior: hay en ella más esbeltez, más precisión de dibujo, a no ser que lo esfumado de la de Oñate se deba a imprecisión fotográfica. De todos modos es curioso que ese mundo de monstruos que Silóee trajo consigo como bagaje desde Italia, haya trascendido de España a América con otras manifestaciones del arte renacentista. (Figs. 4 y 5.)

Si mis investigaciones no fallan el autor de estos relieves fue Juan de Alcántara nacido hacia 1521, a quien Gómez Moreno menciona entre los discípulos de Silóee (p. 99). Entre 1554 y 1556 estaba aún en España pues edificó con Pedro de Asteasu portadas en las iglesias de San Ildefonso y San Miguel de Granada. La primera ostenta grifos renacentistas en forma de $\mathrm{S}$ (Figs. 10 y 11). Pocos años después aparece en Nueva España pues en la información de Diego de Aguilera que' hemos citado, 
dice que en 1594 llevaba más de cuarenta años en la colonia. Esto parece exagerado: la primera noticia que de él tenemos data del 6 de diciembre de 1563 en que informa acerca de la reparación de la catedral vieja de Puebla y presenta dos trazas, que no son como cree Marco las archifamosas de Gómez de Mora o Juan de Herrera para la catedral nueva, sino dos modestas trazas dibujadas por el propio Alcántara en que muestra, en una el estado del templo como existía y en la otra su proyecto de ampliación, agregándole dos naves de capillas hornacinas y una capilla mayor. ${ }^{8}$ Es de creerse que realizó la obra y de Puebla pasó a Oaxaca pues allí en 1572 celebró contrato en unión de Juan de Vega para la obra del encañado del agua por mil ochocientos cincuenta pesos con el cabildo de Antequera. "En el acta del cabildo de la ciudad de México de 4 de septiembre de 1573 se le menciona: "E porque esta ciudad es informada que en la ciudad de Guajaca está un español que se nombra Juan de Alcántara el qual es persona que sabe y entiende de hazer encañados buenos y suficientes e que viniendo a esta ciudad podrá hazer los encañados della..." Nada de extraño era que los arquitectos supiesen hacer acueductos y cañerias pues sabemos que en México el mismo Arciniega se ocupó en la traída del agua de Santa Fe. En mayo de 1575 estaba ya en la capital pues rinde informe con Arciniega y Becerra sobre las obras del convento de Santo Domingo. ${ }^{10} \mathrm{El}$ hecho de verle equiparado con dos de los más notables arquitectos que pasaron a Nueva España en el siglo.xvi indica que no era poco su prestigio. Durante su permanencia en Puebla en 1563 y los años que siguen bien pudo realizar la portada de la Alhóndiga. Claro que falta la comprobación histórica de esta hipótesis o sea el contrato celebrado con el Ayuntamiento de Puebla que debe haber existido, caso de ser cierta, en el archivo del cuerpo edilicio.

Haya sido Juan de Alcántara u otro maestro del arte de cantería el autor de estos relieves, ellos muestran por su semejanza con los que realizó Silóee en España, así como los antecedentes marcados antes en'este breve estudio, la persistencia del espíritu artístico del gran maestro y su prolongación hasta los lejanos ámbitos de la colonia preferida por la metrópoli.

8 Enrique Marco Dorta. Fuentes... p. 34.

9 Gay. Historia de Oaxaca. II, p. 175.

10 Enrique Marco Dorta. Idem. p. 108. 


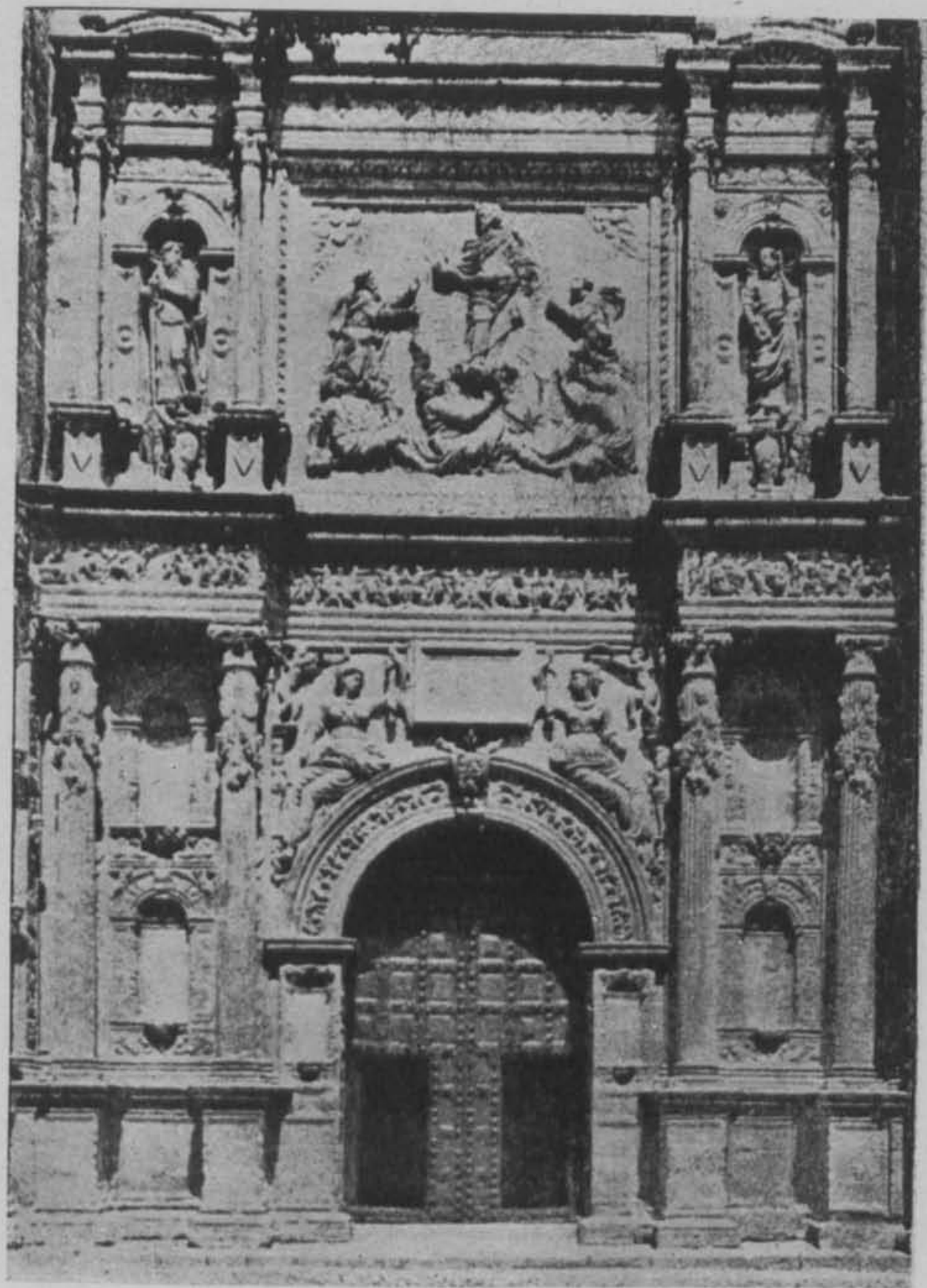

1. Portada principal del templo de San Salvador. Ubeda. España. (Clisé Gómez Moreno.) 


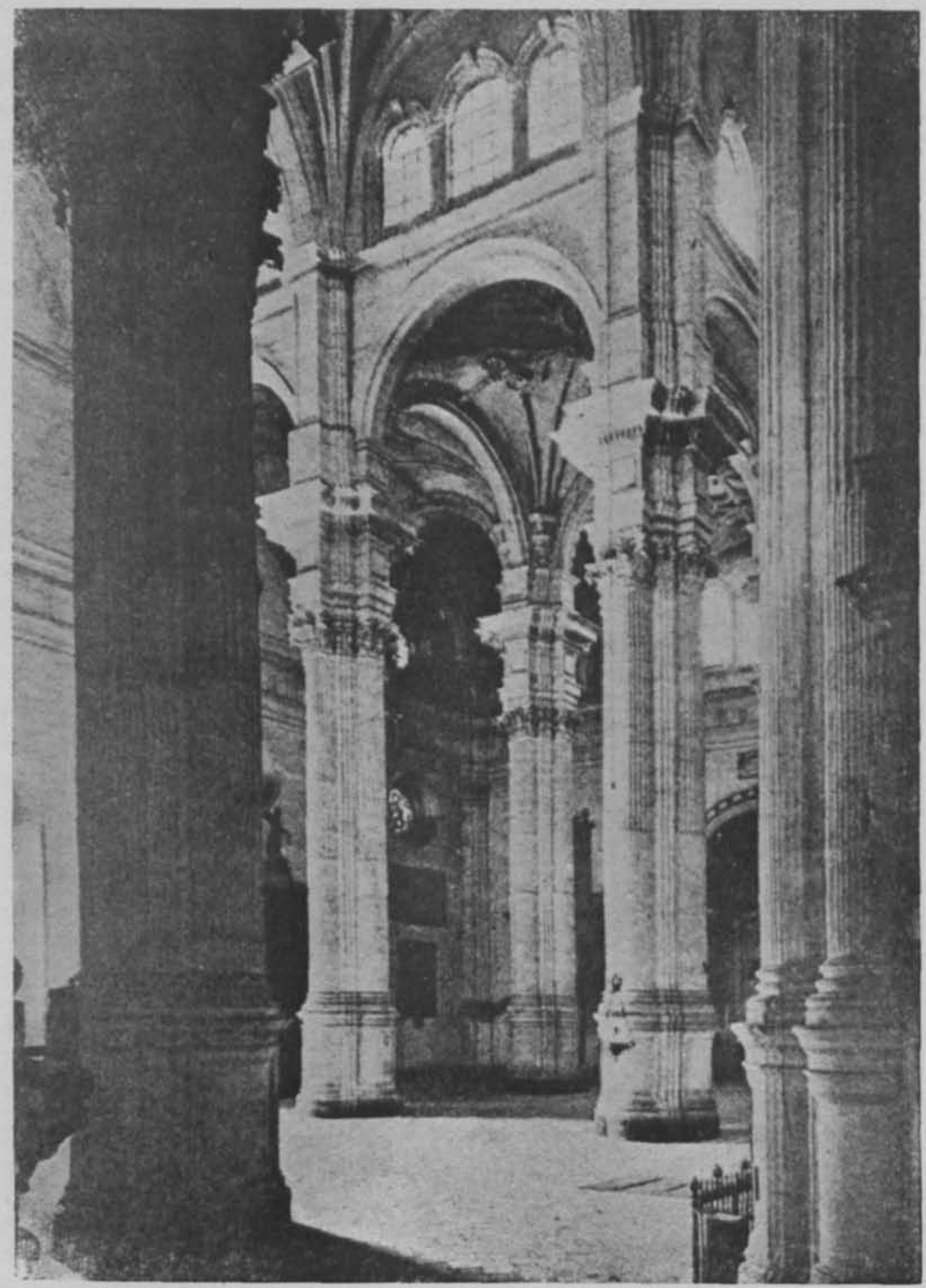

2. Interior de la Catedral de Granada. (Clisé Gómez Moreno.) 


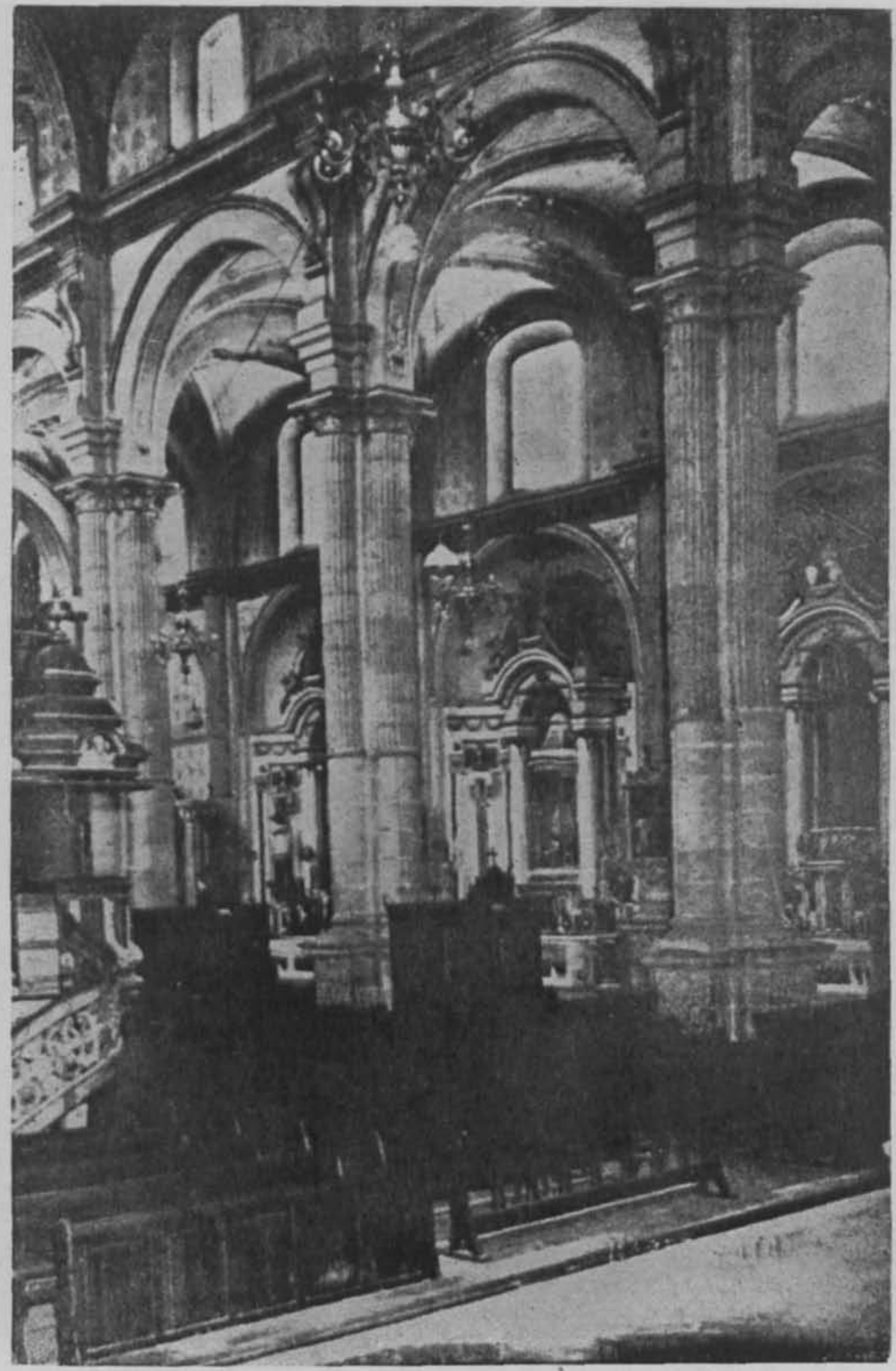

3. Interior de la iglesia de la Compañia de Jesús. Puebla. (Clisé Ibáũez.) 


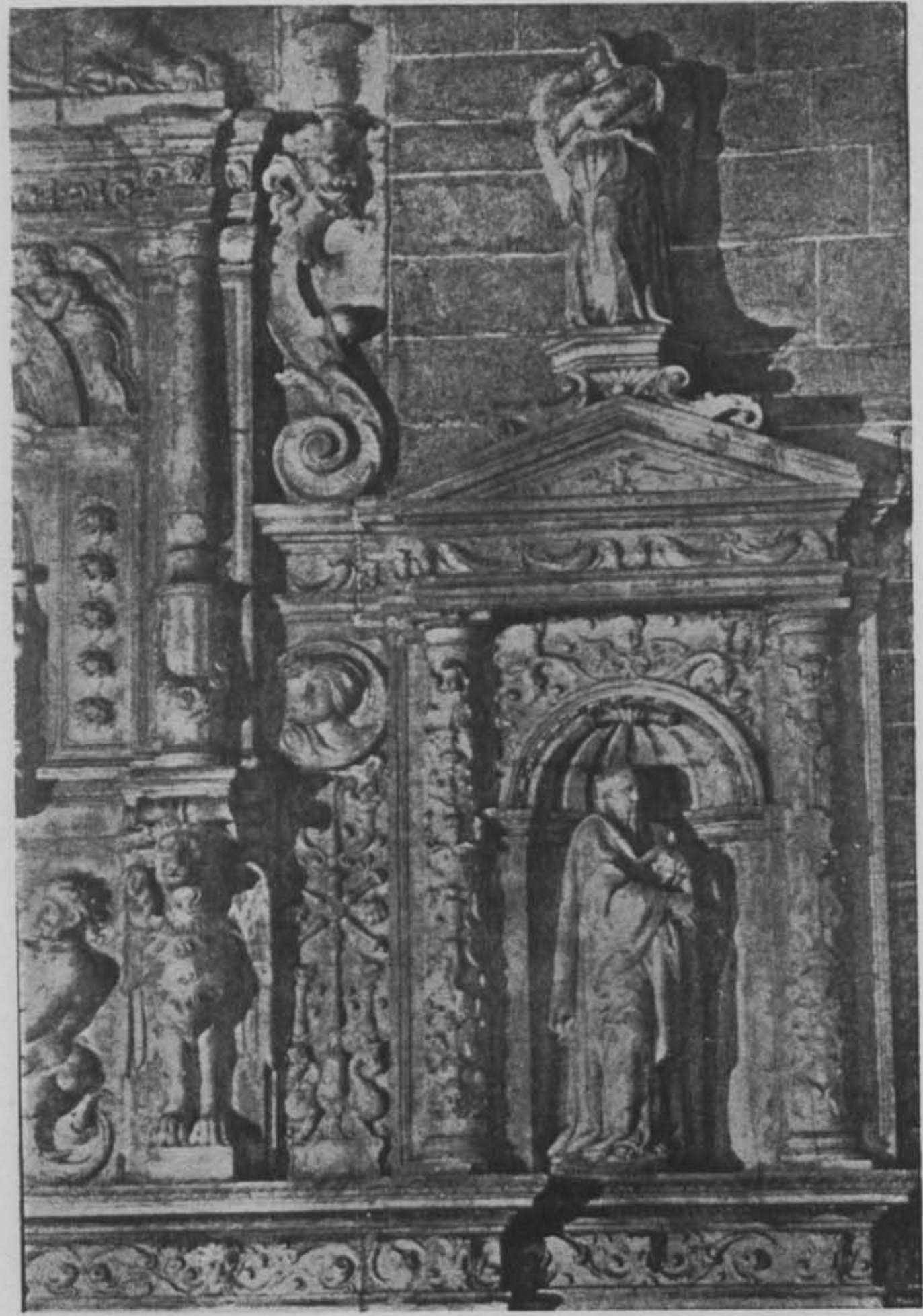

4. Sepulcro del obispo don Rodrigo de Mercado. Detalle. Parroquia de Oñate. España. (Clisé Gỏmez Moreno.) 


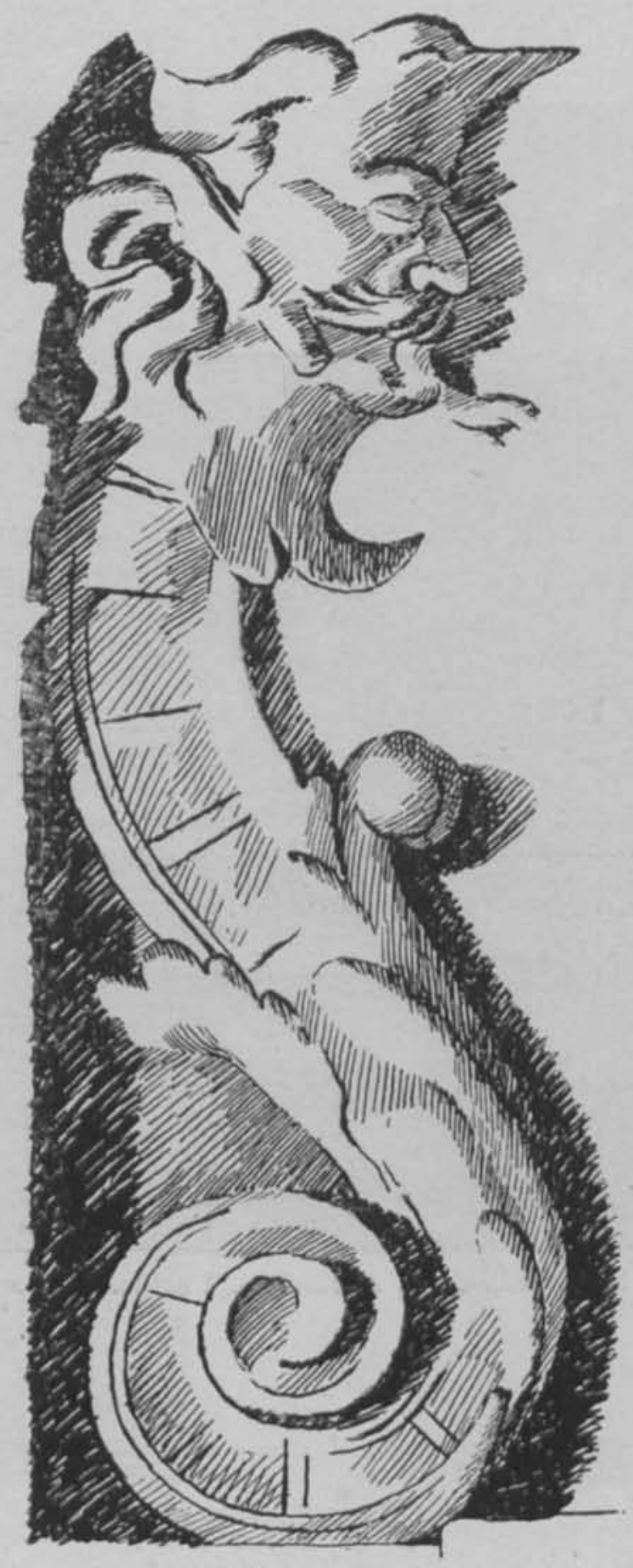

5. Relieve en Oñate. España. (Dibujo de Oscar Frias.) 
DOI: http://dx.doi.org/10.22201/iie.18703062e.1953.21.558

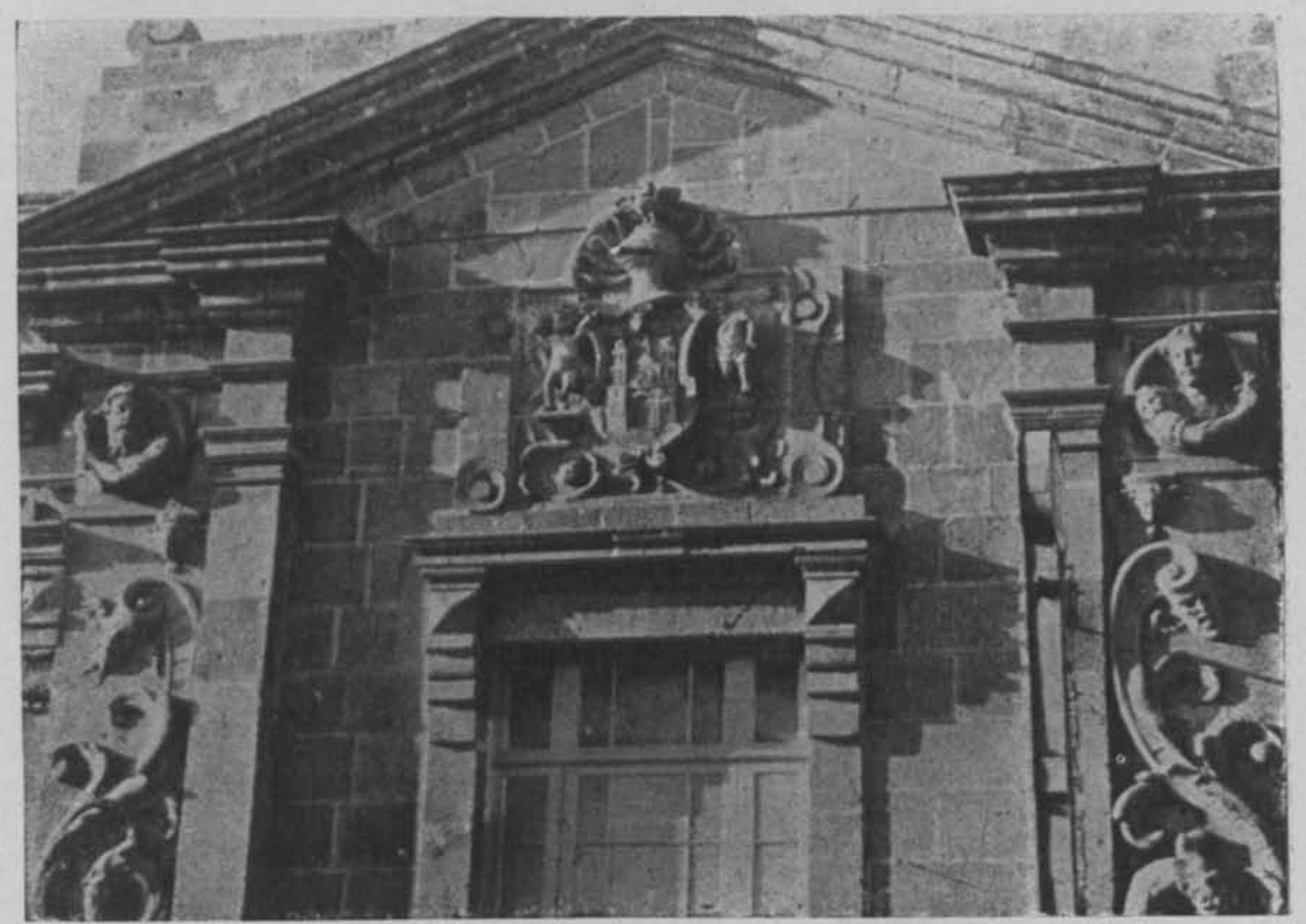

6. Restos de la portada de la Alhóndiga. Puebla. (Foto F. de la Maza.) 

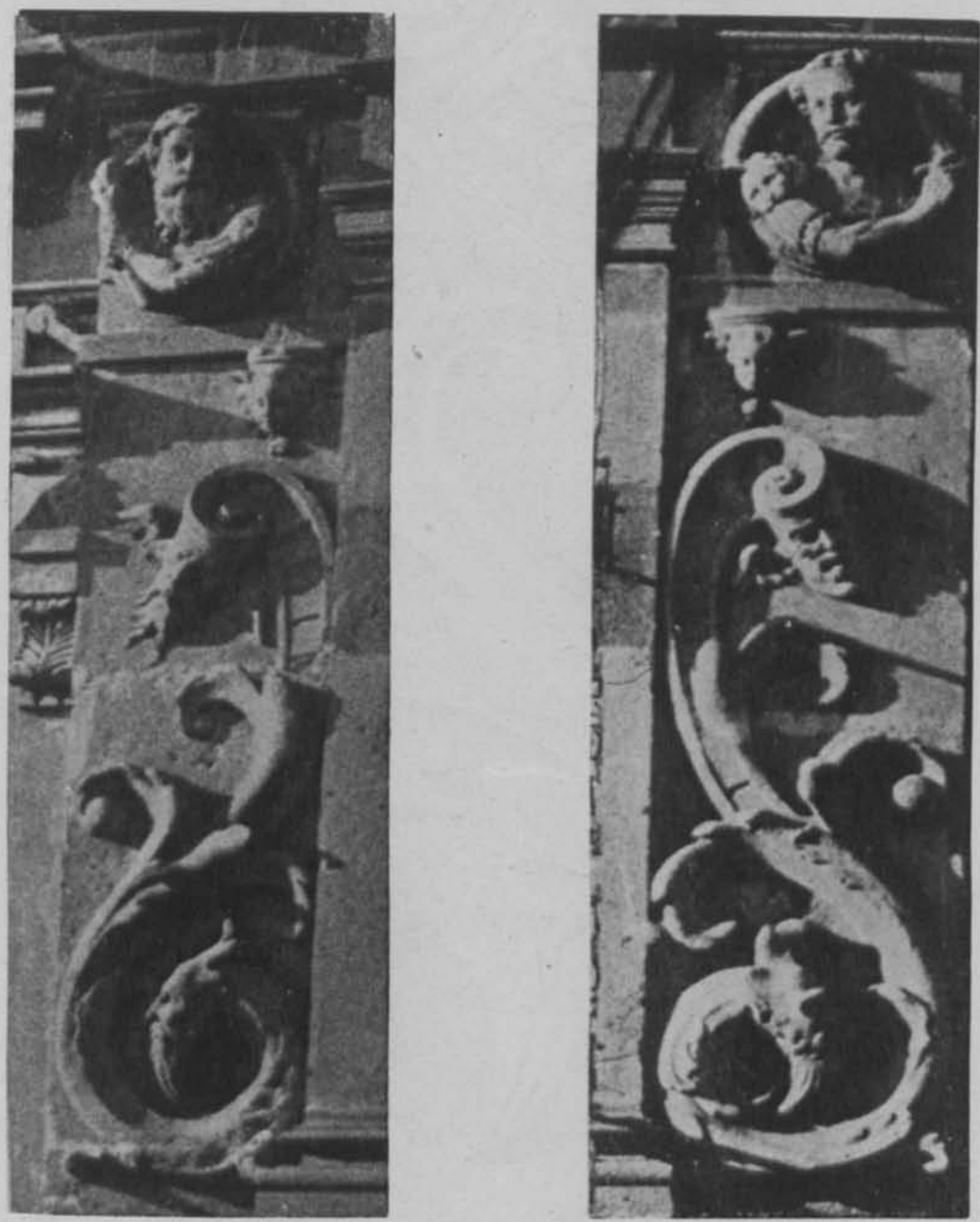

7 y 8 . Detalles de la fachada de la Alhóndiga. Puebla. (Fotos F. de la Maza.) 


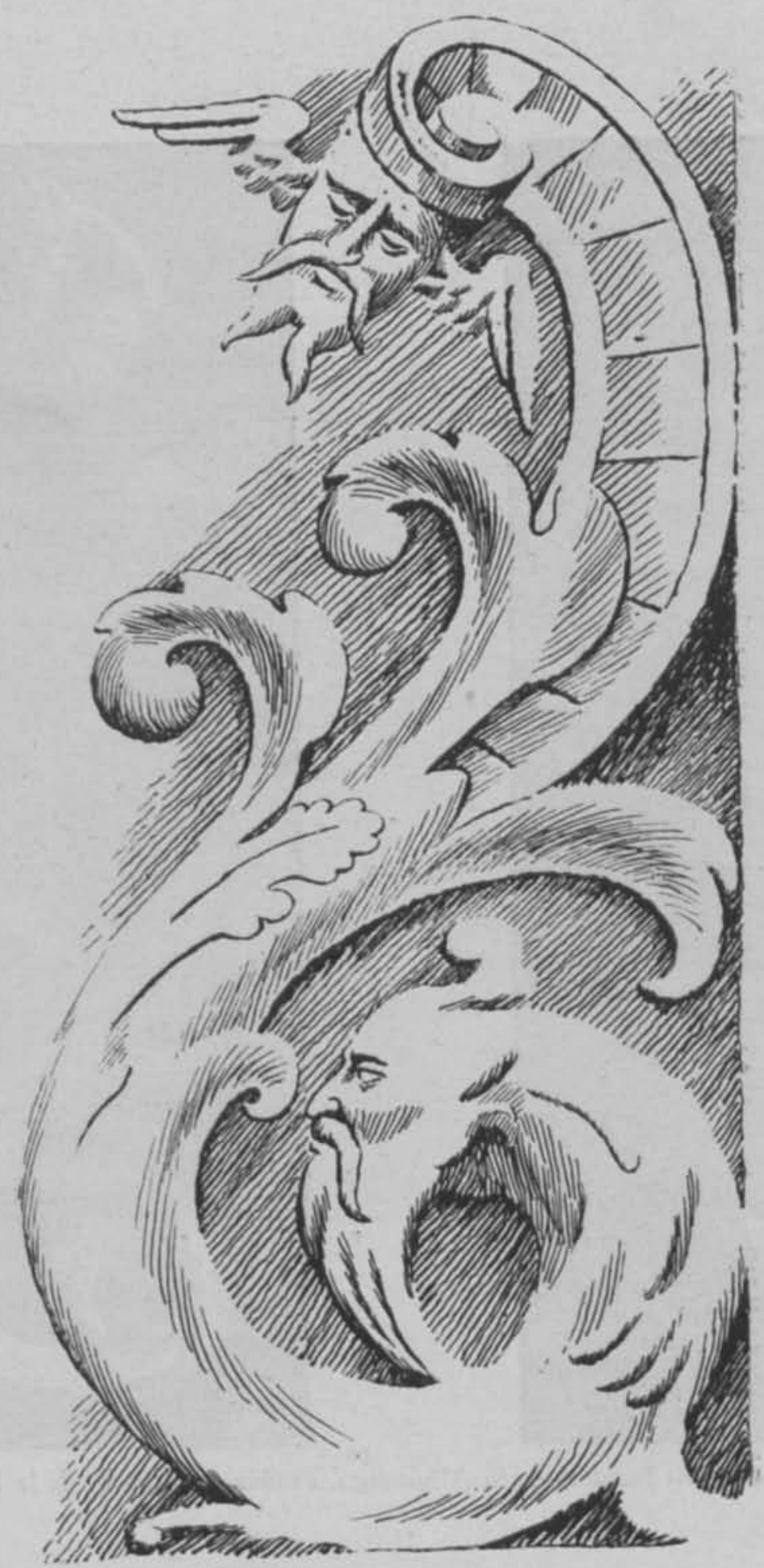

9. Detalle de la fachada de la Alhóndiga. Puebla. (Dibujo de Oscar Frias.) 


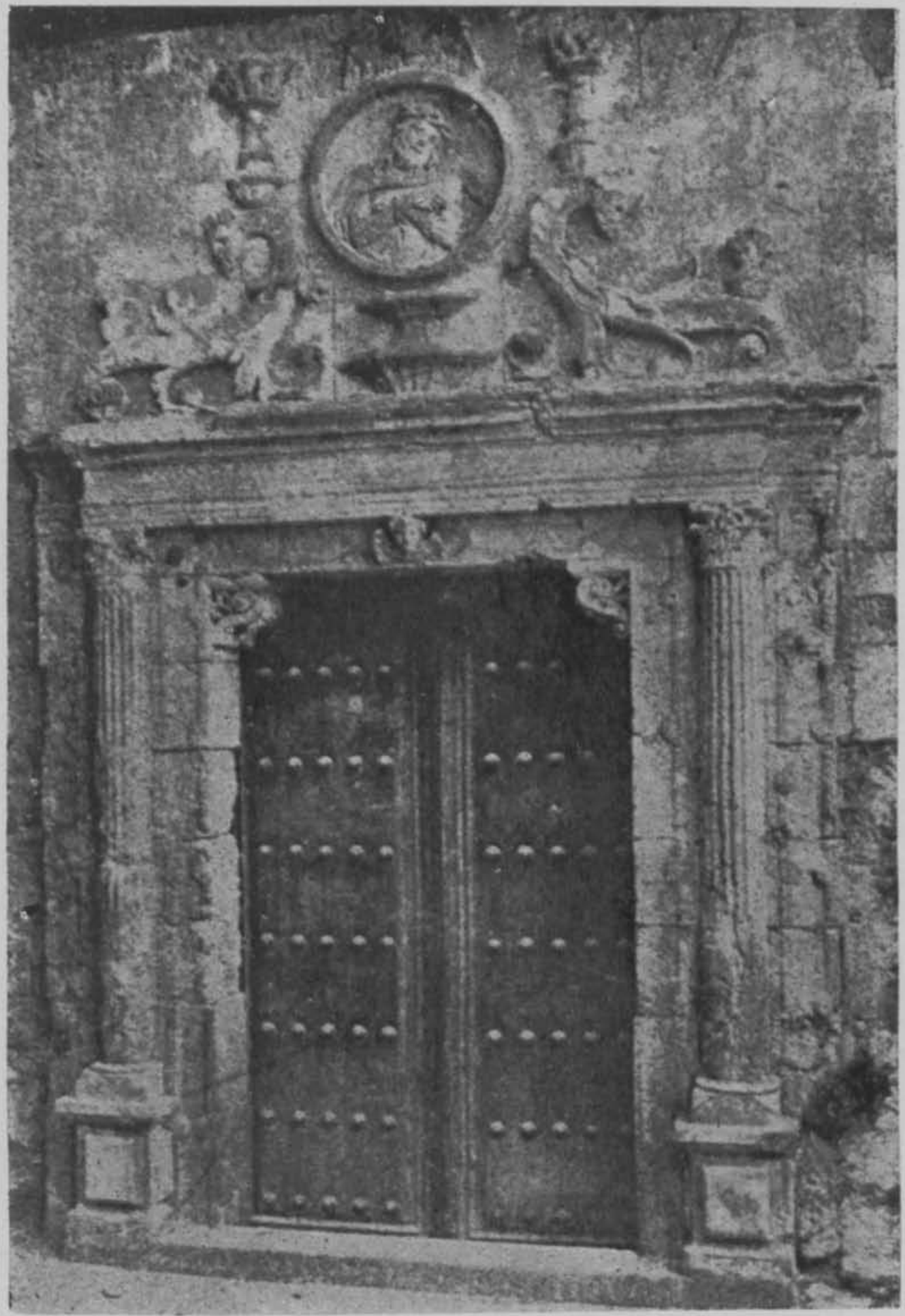

10. Portada de la iglesia de San Ildefonso. Granada. España. (Clisé Gómez Moreno.) 
DOI: http://dx.doi.org/10.22201/iie.18703062e.1953.21.558

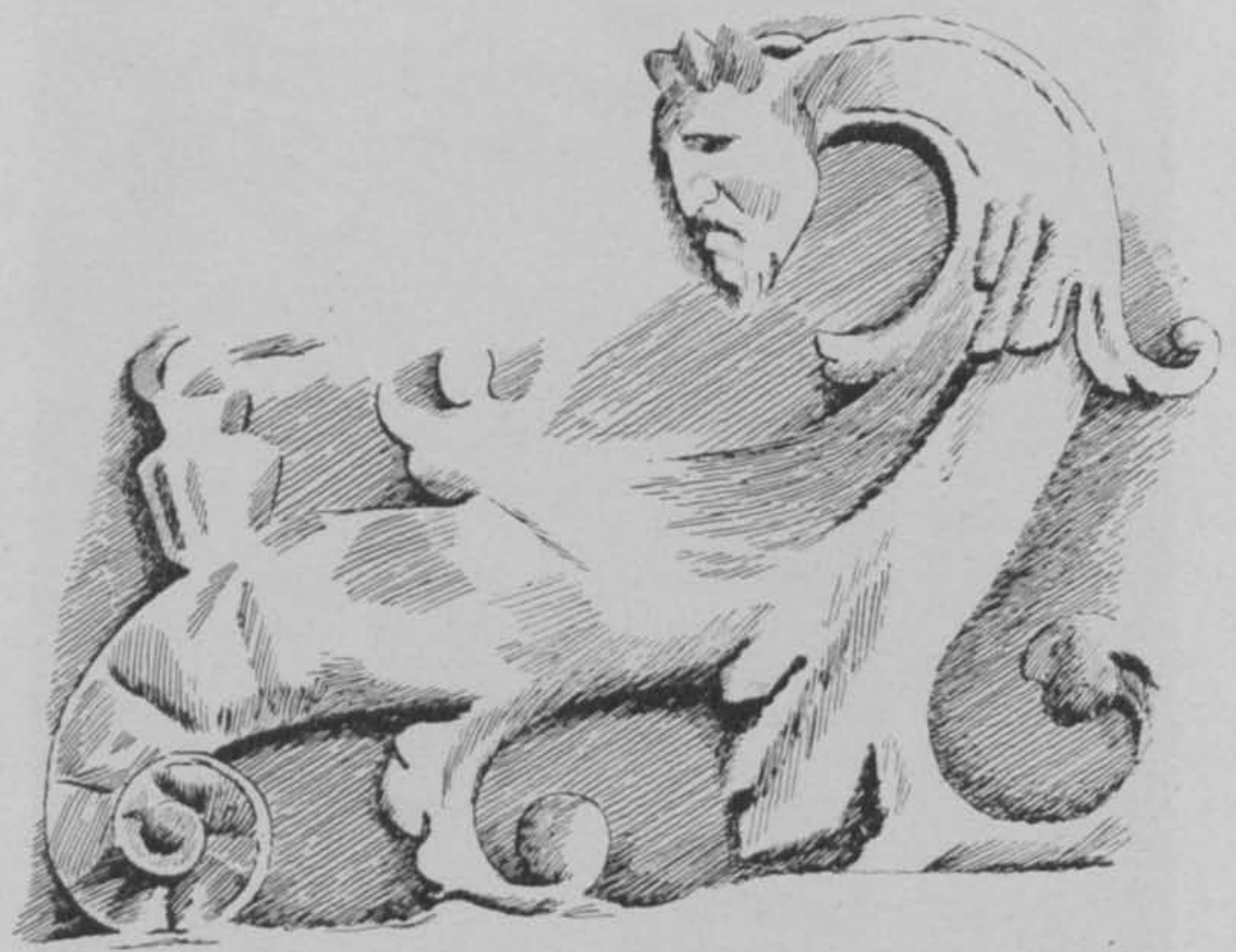

11. Relieve en la iglesia de San Ildé́onso. Granada. España. (Dibujo de Oscar Frias.) 